\title{
Veredas
}

Revista de Estudos Linguísticos

https://periodicos.ufff.br/index.php/veredas/index

\section{On the Theory of Ritual Frame Indicating Expressions: a conversation with Juliane House and Daniel Kádár, discussing Goffman's ideas}

\author{
Krícia Helena Barreto ${ }^{1}$, Carolina Scali Abritta² ${ }^{2}$ Juliane House ${ }^{3}$, Daniel Kádár ${ }^{4}$ \\ ${ }^{1}$ Instituto Federal de São Paulo, Campus São Paulo Pirituba, Brazil; ${ }^{2}$ Universidade do Estado do Rio de Janeiro, Brazil; \\ ${ }^{3}$ University of Hamburg, Hamburg, Germany, Hellenic American University, Athens, Greece; ${ }^{4}$ Dalian University of \\ Foreign Languages, Dalian, Liaoning, China, Hungarian Research Institute for Linguistics, Budapest, Hungary
}

Recebido em: 27.04 .2021

Aceito em: 30.05 .2021

\section{ABSTRACT}

In March 2021, we met virtually with Juliane House and Dániel Kádár. We asked them first about their recent Ritual Frames Indicating Expressions Theory and then about their broader research framework. We also discussed links between their theory and the ideas of the eminent sociologist Erving Goffman. The results of this conversation are what we present here in the form of an interview.

\section{KEYWORDS:}

Erving Goffman. Ritual Frames Indicating Expressions Theory. Cross-cultural Pragmatics.

\section{Introduction}

In January of this year, we became aware of Veredas Journal's call for a thematic issue honoring Erving Goffman. It occurred to us that, in an issue about one of the greatest exponents of symbolic interactionism, it would be relevant to present an interview dedicated to Goffman's notion of 'ritual'. We have recently read, in our study group, thought-provoking research by two linguists who have been working together for a long time on contrastive pragmatic research, namely

\footnotetext{
${ }^{1}$ E-mail: kricia.barreto@ifsp.edu.br | ORCID: 0000-0002-9478-6360

${ }^{2}$ E-mail: carolabritta30@ gmail.com | ORCID: 0000-0001-7638-7764

${ }^{3}$ E-mail: julianehouse@fastmail.fm | ORCID: 0000-0002-6937-1331

${ }^{4}$ E-mail: dkadar@fastmail.com | ORCID: 0000-0002-7238-730X
} 
Juliane House ${ }^{5}$ and Dániel Kádár 6 . Their work revolves around the notion of 'ritual frame'. Their Ritual Frame Indicating Theory, and also their broader cross-cultural pragmatic theory published in the form of a recent book in 2021, are relatively unknown in Brazil at the moment, and so all this research is worth introducing to our domestic readership. Also, importantly for the current Special Issue, the work of House and Kádár is very strongly anchored in various fundamental notions of Goffman, such as 'ritual', 'frame' and 'face'. This led to our idea of virtually meeting with these two researchers, who we asked to discuss the relationship between their theory and Goffman's world. In this report, we feature a transcript of this conversation with House and Kádár. This conversation was enriching for us and we believe that many readers will also be interested in the Goffmanian study of language use proposed and its relationship to the work of House and Kádár.

\section{Interview}

Interviewers: First of all, we would like to say how much it honors us, the interviewers and the guest editors of this issue of Veredas Journal, to be able to learn from two outstanding linguists like yourselves. The current issue of Veredas is paying tribute to the great thinker of Interaction Studies - Erving Goffman. Having read your publications dedicated to pragmatics, in particular interaction ritual, we see that many of your ideas are rooted in Goffman, particularly his book Interaction Rituals (1967). Along with the Goffmanian notion of 'ritual' itself, and other ritual-related notions, you systematically use the concept of 'ritual frame' and, in this way, you interconnect your research with the Goffmanian concept of 'frame'. So, in this interview we ask you to share your thoughts about how Goffman's microsociology contributed to the studies developed in your theory, and our questions from now on will focus on this point.

\footnotetext{
5 Juliane House is Professor Emerita, Hamburg University, Germany, Distinguished Professor Hellenic American University, USA, Honorary Visiting Professor Dalian University of Foreign Languages, China, and Hungarian Academy of Sciences. She is Past President of the International Association for Translation and Intercultural Studies and co-editor of the journal Contrastive Pragmatics. She has published widely on translation, contrastive pragmatics, discourse, politeness and English as a global language. Her latest books include Translation Quality Assessment: Past and Present (Routledge, 2015), Translation as Communication across Languages and Cultures (Routledge, 2016), Translation: The Basics (Routledge, 2017), Cross-cultural Pragmatics (2021, Cambridge University Press, with D.Z. Kadar).

${ }^{6}$ Dániel Z. Kádár (D.Litt., FHEA, Ph.D.) is Chair Professor and Director of the Center for Pragmatic Research at Dalian University of Foreign Languages, China. He is also Research Professor and Head of Hungarian Academy of Sciences Research Group at the Research Centre for Linguistics, Hungary. He is author of 26 books and edited volumes, published with publishing houses of international standing such as Cambridge University Press. He is coeditor of Contrastive Pragmatics: A Cross-Disciplinary Journal. His research interests include the pragmatics of ritual, linguistic (im)politeness research, language aggression, contrastive pragmatics and historical pragmatics.
} 
Question 1: Why did you choose to apply the socio-cognitive notion of 'ritual frame'? How does this term relate to what was conceived by Goffman as ritual?

\section{Dániel Kádár:}

The idea of interaction ritual comes from Goffman, and we understand that this is a special issue dedicated to Goffman, so let's start from here. Goffman talked about so-called 'contact rituals' in his work, basically meaning that ritual is not limited to ceremonial language use but rather it encompasses practically any form of ordinary language use in which rights and obligations are reinforced. For example, civil inattention ${ }^{7}$ is a typical Goffmanian ritual. So, Goffman's concept of interaction ritual provides a broad understanding of ritual, which also includes ceremonial rituals. Rituals in Goffman's sense operate with an underlying sense of moral order but I am not going to discuss this issue in the current interview.

In my previous work, I studied rituals mostly from a sociopragmatic angle, in a top-down way. What we found, and that's what our theory of Ritual Frame Indicating Expression (RFIE) is about, is that if you look at expressions and other pragmatic units in a bottom-up way, you may be able to elaborate an innovative theory of interactional ritual by investigating what kind of rituals and which ritual contexts these units of analysis indicate.

Juliane House:

When we started to work on our RFIE Theory, we conducted a pilot study of a particular expression - the English please -, by comparing its use with that of its Chinese 'equivalent' qing 请. The basis of our research was the following: I had written a paper on please as part of the well-known CCSARP volume in $1989^{8}$. My paper about the use of please was based on the idea that in some standard situations please is used very differently from how we normally interpret and use this expression: for example, a policeman can utter 'Move your car, please' as a form of upgraded Request. We recognised that this use is licensed exactly because the situation on hand is ritual in Dániel's sense: the policeman has the right to utter this upgraded request, and please here is not a marker of politeness at all but rather it indicates the policeman's awareness of the ritual context. The notion of standard situation fits perfectly with Dániel's pragmatic framework of interaction

\footnotetext{
7 Civil inattention is a term coined by Goffman (1963) to refer to the practice of giving some minimal acknowledgement of the presence of a stranger followed by an avoidance of further eye contact.

${ }^{8}$ HOUSE, J. Politeness in English and German: The functions of please and bitte. In: BLUM-KULKA, S.; HOUSE, J.; KASPER, G. (eds.) Cross-Cultural Pragmatics: requests and apologies. Norwood: Ablex, 1989. (p. 96-119)
} 
rituals. So, we argue that expressions such as please indicate awareness of certain ritual contexts, and this is why we called them 'ritual frame indicating expressions'. Importantly, ritual frame often upsets the pragmatic rules holding for ordinary contexts.

\section{Dániel Kádár:}

Let us stick to this example of a policeman. In my original top-down interactional ritual framework I typically focused on individual ritual contexts: for example, in the case on hand I would have been interested in a top-down interactional analysis of the rite of police interrogation, by using audiorecorded data. One may collect such data (although it is not easy) and engage in a contrastive pragmatic analysis of the ritual of police interrogation across cultures. This topic is in itself interesting. However, what I found beautiful in Juliane's work - and that is why we have combined our forces - is that one can also engage in a bottom-up investigation of rituals, by looking at the ritual contexts which a particular expression or other unit of analysis indicates. For example, one may explore the indicatory functions of please. In a top-down logic one may simply argue that please is often used in English language police rituals. This argument in itself is not particularly intriguing. However, if you consider whether please is used in the ritual practices of a police force in one particular linguaculture and, if yes, in which contexts it emerges, and compare this use with the equivalents of please by investigating the contexts such equivalents indicate, you may be able to unearth significant cross-cultural pragmatic differences and similarities in terms of ritual language use. If your research results indicate that equivalents of please do not indicate police contexts in some cultures, you may also investigate the sociopragmatic question of why such equivalents are missing from police rituals in certain linguacultures ${ }^{9}$. Going a step further, if you systematically model linguacultural variation between the ritual contexts please and its equivalents, you may be able to map a cluster of ritual situations indicated by this particular expression. This investigation opens the road to investigate more than just an expression, and also to explore the relationship between expressions and related speech acts through the lens of interaction ritual.

\section{Juliane House:}

At this point, it is useful again to refer back to my 1989 paper which I mentioned before. Actually,

\footnotetext{
9 "Linguaculture (or languaculture) is a concept that focuses on culture in language or the cultural dimensions of language. It has been developed to contribute to a more differentiated conceptual frame in the interface between studies of language and studies of culture." (Bennett, 2015)
} 
what gave impetus to our joint research was a fact that I pointed out at the time, perhaps before than anyone else noting this problem, namely that please has nothing to do with politeness by default. Expressions such as please have often been called 'politeness marker' but what they often indicate is not politeness but the use of certain speech acts and the related ritual context(s). So, what I pointed out at the time was that please is actually a marker of the speech act of Request. This is why, when we started to work with Dániel, I saw the relevance of his interactional ritual framework to the systematic study of such expressions and related speech acts. As a result of our collaboration, we formed our 'Ritual Frame Indicating Expressions' (RFIE) Theory'10, which emphasizes that such expressions have relatively little to do with politeness.

As part of developing this framework, Dániel and myself have engaged in research of strongly contrastive pragmatic scope, and our RFIE Theory is also of a contrastive nature. When we study expressions such as please and sorry, it is particularly fruitful to consider their ritual frame indicating functions by comparing their uses with that of their counterparts drawn from typologically distant linguacultures such as Chinese. We found, for instance, that while in everyday buying and selling scenarios, where in English one can always use the expression please (e.g. 'can I have two oranges, please?'), the Chinese expression qing cannot be used at all in similar standard situations. Such a pragmatic difference is significant not only due to its practical implication for language learning, translation and other areas, but also because it helps us to work toward the cross-cultural mapping of interaction rituals. Such cross-cultural differences can only be captured if one does not look at grand intercultural generalisations but rather engages in a 'pedestrian' pragmatic examination of seemingly 'simple' expressions, with the aid of large corpora. And from such a modest investigation, one may work up one's way to the systematic study of the interface between expressions, speech acts and discourse itself, to be investigated through the lenses of ritual and ritual frame.

\section{Krícia Barreto:}

Your RFIE Theory really changes how we see things. Your example of please reminds me of language use in institutions here in Brazil where they often use such so-called 'politeness markers' in a rather ironic way. So they obviously don't use such expressions to be polite, but rather to

\footnotetext{
${ }^{10}$ HOUSE, J.; KÁDÁR, D. Cross-cultural pragmatics. Cambridge: Cambridge University Press, (in press). HOUSE, J. et al. Interaction, speech acts and ritual: An integrative model. Lingua. 2021 (in press). Can be downloaded in Open Access at the following link: 
frame the situation and make other speech acts.

Juliane House:

Exactly. We also encountered this phenomenon very often in our data. For example, in our study of the expression sorry we found that the use of this expression has often nothing to do with the speech act of Apology and related politeness. Rather, sorry can realise a very rude interruption (e.g. 'sorry what do you mean?'). As such, it can express irony and other non-polite meanings.

\section{Dániel Kádár:}

What Krícia just mentioned - please, sorry and other so-called 'politeness markers' realising meanings such as irony, sarcasm and so on - is a very important aspect of our RFIE Theory. It is possible to systematically model such uses from a bottom-up angle, in particular if you consider linguacultural variation. For example, in certain linguacultures such as the Chinese and the Japanese, such expressions tend to be used according to their default speech act-anchored way, while e.g. in English other uses such as the expression of irony can be as conventionalised as the speech act-anchored use itself. Exploring such linguacultural variation allows us to tap into some major cross-cultural pragmatic differences between linguacultures in terms of how irony and pragmatic phenomena are systematically realised through lexical items and various related ritual questions.

Juliane House:

On a related note, by elaborating a cross-cultural pragmatic model, partly with the aid of our RFIE Theory and also by going beyond this theory and focusing on other pragmatic units, we also conducted a critical reinvestigation of discursive views that deny the modellability of cross-cultural differences and similarities. In our recent Cambridge University Press book (HOUSE; KÁDÁR, 2021), which will be out later this year, we rather drastically talked against fetishising audiorecorded data capturing idiosyncratic language use, which many discursive scholars emphasised as the non plus ultra of pragmatic research. We believe that it is very important to examine linguaculturally embedded (conventionalised and ritual) patterns of language use with the aid of large corpora, as well as by using other ancillary methodologies. Any research, in particular cross-cultural pragmatic research, should ultimately work towards systematising language use, and interaction ritual theory and related notions provide a key to achieve this goal. 
Question 2: Do you think we can merge both methodological perspectives (bottom-up and topdown) in a single work when studying interaction ritual, politeness and impoliteness and other pragmatic phenomena, or do you think we should make a choice of working with either one or the other? This seems to me a particularly important question, considering that many pragmaticians with interest in Goffman's work may want to adopt a bottom-up view, considering that many of Goffman's ideas such as 'civil inattention' can only be understood in a bottom-up way, as you recently pointed out in a paper published in Pragmatics (2020).

\section{Dániel Kádár:}

Bottom-up and top-down research are actually not in opposition. Juliane argued that one should preferably rely on corpus-based methodologies in cross-cultural pragmatic research, including the RFIE Theory, and such corpus-based research is usually bottom-up. However, one can complement such research: we call this procedure 'ancillary' research. As far as interactional ritual is concerned, there is no reason why one could not look first at corpora, and then complement such research with top-down methodologies, involving discourse analysis.

Juliane House:

In connection with this point, it is also worth noting that one not only needs to merge bottom-up and top-down methodologies, but also one needs to focus on various units of analysis in crosscultural pragmatic research. In our recent book, we set up a model of cross-cultural pragmatic analysis, consisting of three levels: the lowest of them consists of expressions, the next level of speech acts and the highest one of discourse. These are separate levels of analysis but of course they are intrinsically interconnected. For example, one can start a particular research by focusing on discourse and systematically compare units that constitute discourse across linguacultures. For instance, a type of talk such as small talk is a typical ritual unit of discourse. But one can also proceed the other way around, and in the examination of expressions and speech acts consider their discursive use. So, along with merging bottom-up and top-down, it is also fundamental to make a holistic use of various units in our analysis. This is also an idea which comes from Goffman: in the analysis of social interaction all these units are intertwined. 
Question 3: To finish this interview, we would like to return to Goffman's contributions to your studies on ritual frame. Did your Goffmanian background make your theory different from other pragmatics-influenced theories of politeness and other related phenomena?

Juliane House:

This is exactly the case. For example, we broadly used Goffman's notion of conversational 'move' to systematise discourse from a cross-cultural pragmatic point of view, somewhat differently from how research inspired by conversation analysis has proceeded. More precisely, our conceptualisation of interaction is centred on the ritual dynamics of a given interaction in Goffman's sense. One can capture such dynamics in any interaction through a structure of interactional moves, which are combined in recurrent (ritual) forms of exchanges. In the analysis of ritual frame, in particular if we move above the level of expressions, these notions are essential. Again, it is worth here to refer to the fact that expression is only the smallest unit in our crosscultural model, and the notion of 'ritual frame' spans across our various units of analysis. Goffman's theory imbues all our analytic concepts!

\section{Dániel Kádár:}

In the research of ritual, and also in research inspired by ritual, one cannot avoid talking about Goffman! For example, it was Goffman's theory that helped me to realise that we often overstretch the expression 'politeness', and many pragmatic phenomena we study are more 'ritual' than 'polite' in scope. I dedicated a book (2017) $)^{11}$ to this issue. Ritual and politeness indeed have a very complex relationship and it is not a coincidence that Goffman wrote a lot about ritual but he very rarely used the word 'politeness'. It is perhaps not overly ambitious to say that ritual is way more prevalent in our daily lives than politeness in the narrow sense of the word at least. Very often, in ritual language use there is no need for intricate facework, as Juliane also pointed out as early as 1989, in Goffman's sense. In many ceremonial rituals, face only emerges if the moral order or the operation of the ritual gets violated, but the same goes for contact rituals emerging in very many daily life scenarios. The importance of the Goffmanian notion of ritual prompted me to focus on this phenomenon and bring it together with other notions in the framework Juliane and myself have created.

11 KÁDÁR, D. Politeness, Impoliteness and Ritual: maintaining the moral order in interpersonal interaction. Cambridge: Cambridge University Press, 2017. 
Juliane House:

Let me expand on what Dániel mentioned. Our framework is significantly different from mainstream politeness research, and indeed we tried to avoid using many buzzwords dominating the field of politeness. For example, Dániel and I agreed that we will not use '(im)politeness' with brackets in our work. This is not only because politeness and impoliteness are different but rather we wanted to disalign ourselves from certain now-established conventions in the field. For example, we objected that the field goes to a very drastic direction of overemphasising evaluation over production. Scholars such as Goffman were - quite rightly - not interested in evaluation and other notions such as getting offended that much. Language users do not always madly evaluate utterances, and overemphasising evaluation - however important it may be sometimes - kills the opportunity of doing replicable cross-cultural pragmatic analysis focusing on interaction ritual. So, in our framework we attempted to return to Goffman by taking various of his key notions on board.

\section{Dániel Kádár:}

Our theory, including interactional ritual theory, also provides insight into certain neglected aspects of interaction. In particular, it draws attention to language use in certain precarious settings, such as military trainings and other 'rough' settings, which are ritual in scope and which have been relatively neglected in pragmatics. The same applies to many seemingly insignificant daily interactions, such as Juliane's case of police request. Many of such settings are, as Goffman pointed out, communal rituals. In the study of language use in these settings, the conventional repertoire of politeness research is of little use. Take an army setting as a drastic example. When your corporal screams at a private, he may feel offended but practically nobody will care about his little feelings. This is why evaluation, linked to the notion of offence, is very often of secondary importance in interaction ritual-anchored pragmatic theory. And, if you consider daily interactions, many contexts are rather similar to the extreme example of military trainings, i.e. we very often participate in communally-oriented contact rituals, in Goffman's sense, in which individual evaluations exist but are of secondary importance, and even 'politeness' and 'impoliteness' themselves are clearly backgrounded.

Juliane House: In sum, we can answer: 'yes', many of Goffman's ideas have influenced our ritual frame-anchored cross-cultural pragmatic framework. It is also Goffman's influence that our 
framework is somewhat different from the 'mainstream' of linguistic politeness research.

Krícia Barreto:

Methodologically speaking, I feel that your framework makes our lives easier due to its systematic focus on the replicable elements of language use through the lens of conventionalised ritual behaviour.

Juliane House:

We hope so. For scholars who work with big discourse notions our approach may appear to be very pedestrian and pedantic. However, we feel that it provides a replicable and essentially pragmalinguistic approach to systematically capture conventionalised aspects of language use across linguacultures.

\section{Conclusion}

In this interview we discussed with Juliane House and Daniel Kádár the foundations of their recent theory. We started with their RFIE Theory and later discussed their broader cross-cultural pragmatic framework, which they published in the form of a book, to be published by Cambridge University Press in 2021. This broader theory captures the replicable aspects of language use in different units through the lens of ritual frame. The work of House and Kádár is intrinsically interconnected with Goffman's seminal ideas. The interviewers believe that the theory presented will prompt a fruitful dialogue between pragmatics and other fields, including applied linguistics, interactional sociolinguistics, corpus linguistics and many other aspects of language sciences.

\section{Recommended references}

BENNETT, Janet (Ed.). The SAGE Encyclopedia of Intercultural Competence. SAGE Publications, Inc. 2015.

GOFFMAN, E. Ritual Interaction: essays in face-to-face behavior. Chicago: Aldine Publishing Company, 1967.

GOFFMAN, E. Frame Analysis: an essay on the organization of experience. Boston: Northeastern University Press, 1986.

GOFFMAN, E. The negligent situation. American Anthropologist, v. 66, n. 6, p. 133-136. 1964.

GOFFMAN, E. Behavior in public places: Notes on the social organization of gatherings. New York: 
Free Press.1963.

HOUSE, J. Politeness in English and German: The functions of please and bitte. In: BLUM-KULKA, S.; HOUSE, J.; KASPER, G. (Ed.) Cross-Cultural Pragmatics: requests and apologies. Norwood: Ablex, 1989. (p. 96-119)

HOUSE, J.; KÁDÁR, D. Cross-Cultural Pragmatics. Cambridge: Cambridge University Press, (in press).

HOUSE, J. et al. Interaction, speech acts and ritual: an integrative model. Lingua. 2021 (in press). Can be downloaded in Open Access at the following link: https://www.sciencedirect.com/science/article/pii/S0024384121000541

KÁDÁR, D. Politeness, Impoliteness and Ritual: maintaining the moral order in interpersonal interaction. Cambridge: Cambridge University Press, 2017.

KÁDÁR, D.; HOUSE, J. Ritual Frames: a contrastive pragmatic approach. Pragmatics, v. 30, n. 1, p. 142-168, 2020. 